\title{
Hydroxyproline Excretion and Collagen Catabolism in Rats of Different Age Groups
}

\author{
S. Mohan ${ }^{1}$ and E. Radha \\ Department of Zoology, Bangalore University, Bangalore-560 001, India
}

Received January 23, 1980

The amount of hydroxyproline in urine is an index to the catabolism of collagen. Diseases like acromegaly, hyperthyroidism, osteoporesis, Marfan's syndrome which are characterized by changes in the metabolism of collagen have made the urinary hydroxyproline determinations more valuable for clinical purposes (1). The profile of urinary hydroxyproline excretion during the 24-hr period in normal rats of different age groups and the significance of such a study are described in this paper.

\section{MATERIALS AND METHODS}

Male Wistar strain albino rats of 5,15 , and 28 months of age were used as experimental animals. Urine samples were collected at 4-hr intervals using a metabolic cage. The samples were collected for 4 consecutive days for each animal and from six animals of the same age group. Four hundred and thirty-two samples were analyzed for urinary hydroxyproline content. Since $90-95 \%$ of the hydroxyproline content in the urine is in bound form, the samples were hydrolyzed at $150^{\circ} \mathrm{C}$ for $3 \mathrm{hr}$ at 15 $\mathrm{lb}$ pressure and the hydroxyproline content was estimated by the method of Kivirikko et al. (2).

\section{RESULTS AND DISCUSSION}

Urine volume and the amount of hydroxyproline content at different time points during the 24 -hr period show that the peak occurs at midnight between 2200 and 0200 . The time at which the peak appears remains the same in all the three age groups studied (Fig. 1). The volume of urine as well as the amount of hydroxyproline excreted are much more during the dark phase when the animals are active compared to the light phase (Fig. 2). Sothern et al. (3) have reported the circadian pattern in urinary

${ }^{1}$ Present address: Department of Pathology, Edmonson Research Building, USC Medical School, 1840 North Soto Street, Los Angeles, Calif. 90032. 


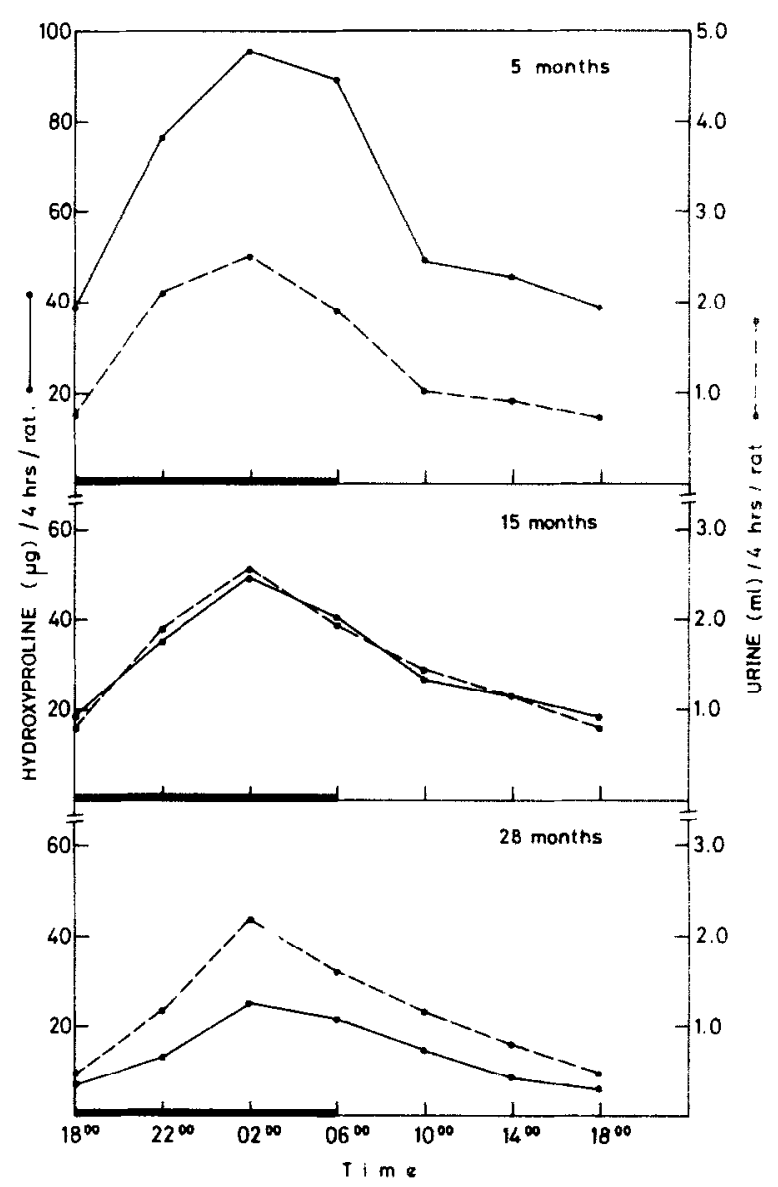

FIG. 1. The amount of hydroxyproline and the volume of urine excreted at 4-hr intervals.

volume and hydroxyproline excreted in healthy humans with the peak appearing during the midday where as in the case of rats which are nocturnal the time at which the peak appears is shifted by $12 \mathrm{hr}$. The volume of urine excreted by a 15 -month-old animal is $9.6 \mathrm{ml}$ during the 24 $\mathrm{hr}$ whereas it is $7.2 \mathrm{ml}$ in the case of a 28 -month-old animal, but there is no significant difference in the volume of urine excreted between a 5- and a 15 -month-old animal $(9.2$ and $9.6 \mathrm{ml} / 24 \mathrm{hr}$, respectively). Similarly there is a marked reduction in the amount of hydroxyproline excreted as the animal ages from 5 to 28 months (Fig. 3). The amounts of hydroxyproline excreted in 5-, 15- and 28-month-old rats are 394.6, 194.3, and $88.8 \mu \mathrm{g} / 24$ $\mathrm{hr}$, respectively. The amount of hydroxyproline excreted decreases by about $77.5 \%$ as the age advances from 5 to 28 months. This decrease with age can be attributed to the increased structural stability of collagen seen 


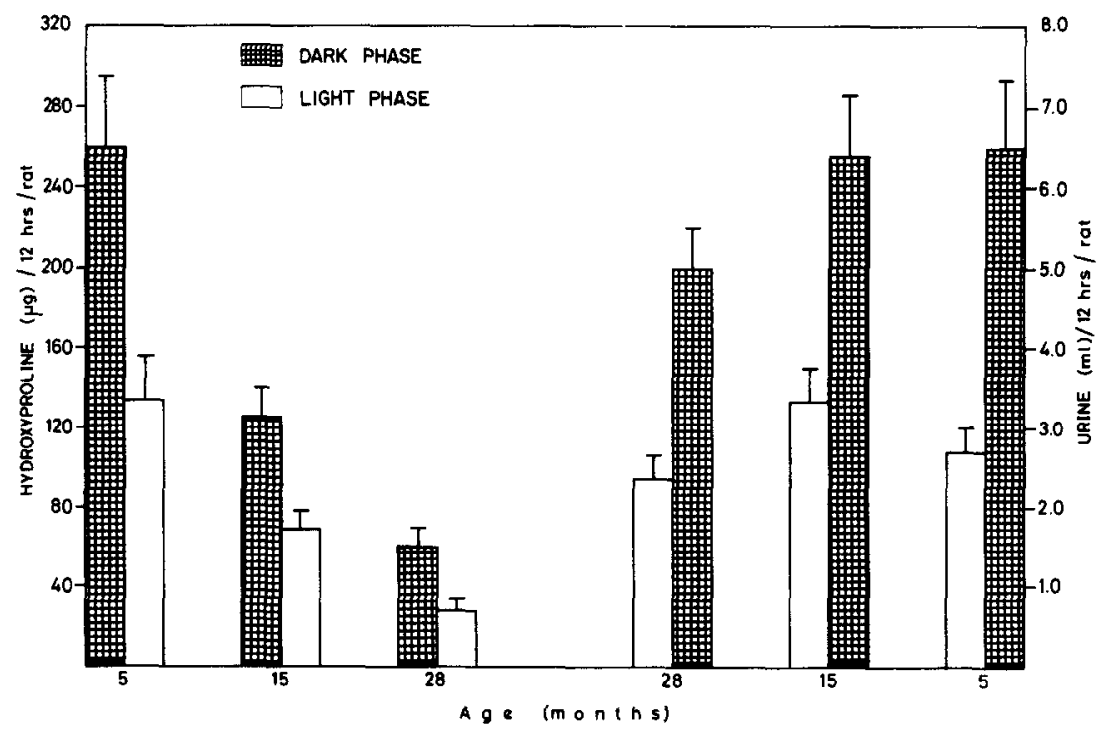

FIG. 2. Amount of hydroxyproline and volume of urine excreted during light and dark phases.

in older animals. The final breakdown products of collagen include both free hydroxyproline and hydroxyproline-containing peptides which are found in tissues. Since free hydroxyproline as well as the bound form are not utilized for the resynthesis of new collagen, these breakdown products are either excreted or catabolized further as shown in Fig. 4. In the kidney, free hydroxyproline is almost completely reabsorbed by the tubuli while the hydroxyproline-containing peptides are rapidly cleared; that is

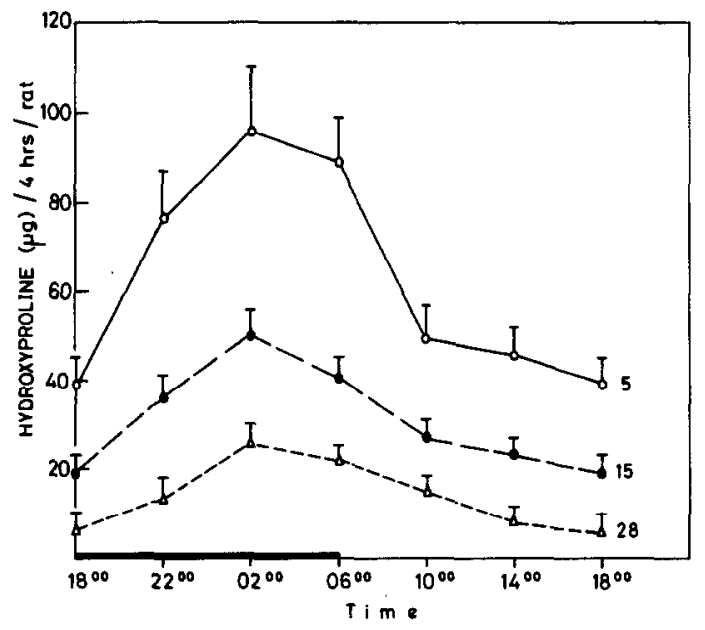

FIG. 3. Age-related change in the excretion of hydroxyproline. 


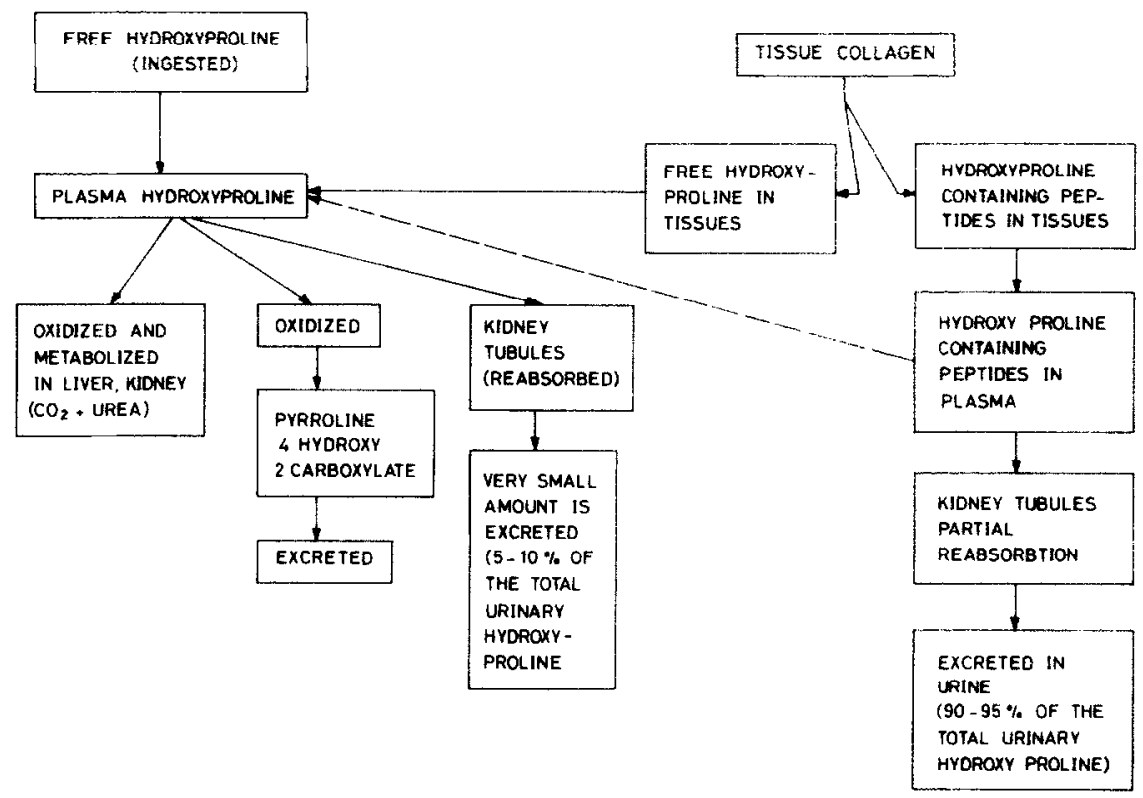

Fig. 4. Model scheme for the relationship of urinary hydroxyproline excretion to the metabolism of collagen.

why $95 \%$ of hydroxyproline in urine is excreted as bound form and only less than $5 \%$ as free amino acid. Free hydroxyproline is further catabolized in the liver and kidney.

Excretion of hydroxyproline content in urine depends on a number of factors such as (i) the rate of synthesis of new collagen, (ii) rate of degradation, and (iii) collagen crosslinking as shown in Fig. 5. The newly synthesized fraction of collagen which is more susceptible to the activity of the collagen-degrading enzyme decreases with age (4) while the amount of insoluble collagen which is less susceptible to the action of the enzyme increases significantly with age due to crosslinking. Furthermore the activity of the collagen-degrading enzyme decreases significantly with age as a result of which the rate of collagen catabolism is markedly decreased in old animals.

The present results have clearly shown the importance of the study of the excretory pattern of hydroxyproline over a 24-hr period for diagnosis and clinical practice as it would be misleading to have a single sample reference.

\section{SUMMARY}

Hydroxyproline as an index of collagen catabolism was studied in 432 urine samples collected from rats of different age groups at 4-hr intervals during the $24-\mathrm{hr}$ period. The results showed statistically significant circa- 


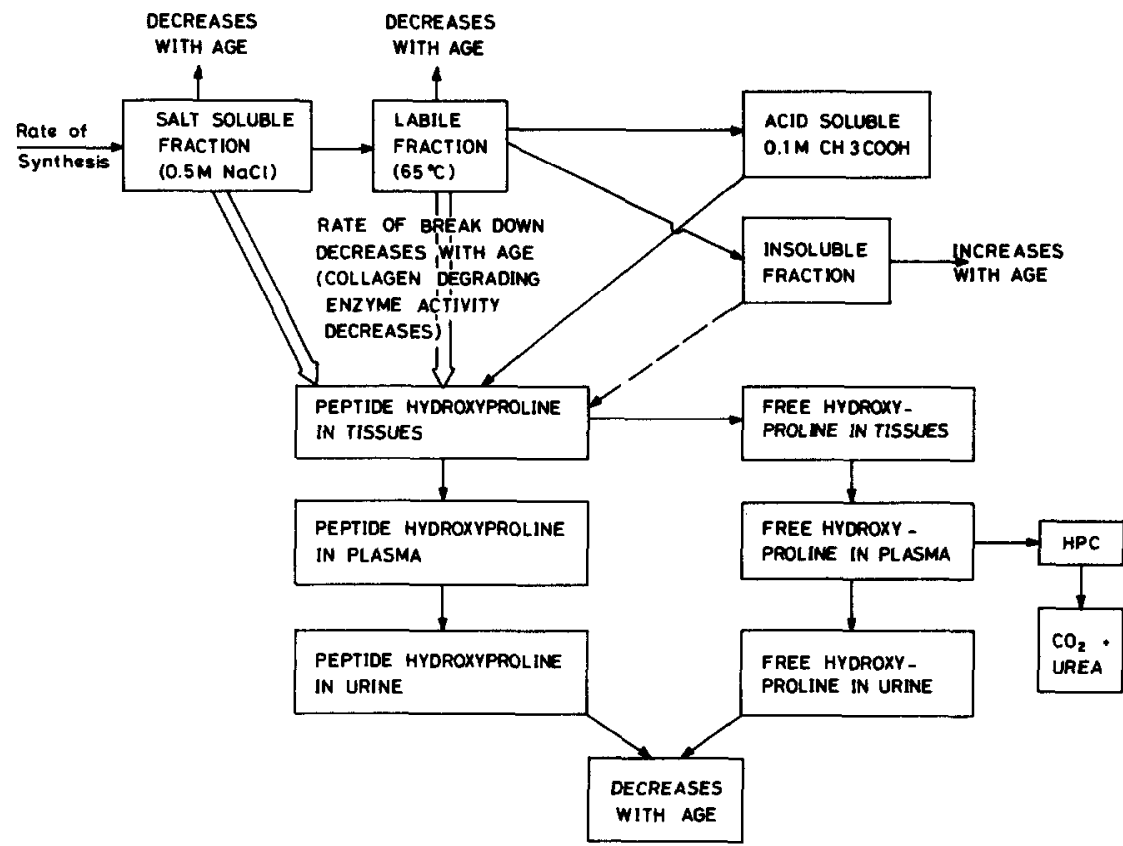

FIG. 5. Model of collagen metabolism as a function of age.

dian rhythm in urinary hydroxyproline excretion with a peak between 2200 and 0200 . The amount excreted is significantly more during the dark hours which can be correlated with the activity cycle. Total amount of excreted hydroxyproline decreases with age. The present results clearly show the importance of the determination of urinary hydroxyproline over a $24-\mathrm{hr}$ period for clinical purposes.

\section{REFERENCES}

1. Laitinen, O., “Oy Til -set." Ab, Helsinki, 1974.

2. Kivirikko, K. I., Laitinen, O., and Prockop, D. J. Anal. Biochem. 19, 249 (1967).

3. Mohan, S., and Radha, E., Gerontology, 26(2), 61 (1980).

4. Sothern, R. B., Leach, C., Nelson, W. L., Halberg, F., and Rummel, J. A., Chronobiologia 1 (Suppl. 1), 73-82 (1974). 